\title{
A rare clinical presentation of pulmonary hypoplasia
}

\author{
Figen Gülen $^{1}$, Sakine Kar ${ }^{1}$, Levent Midyat ${ }^{1 *}$, Esen Demir ${ }^{1}$, Süphan Özyurt ${ }^{2}$, Arif Ruhi Özyürek ${ }^{3}$, \\ Remziye Tanaç ${ }^{1}$, Naim Ceylan ${ }^{4}$
}

\author{
${ }^{1}$ Department of Pediatric Pulmonology-Allergy, Faculty of Medicine, Ege University, Izmir, Turkey; \\ ${ }^{2}$ Department of Pediatric Pulmonology-Allergy, Social Security Tepecik Children's Hospital, Izmir, Turkey; \\ ${ }^{3}$ Department of Pediatric Cardiology, Faculty of Medicine, Ege University, Izmir, Turkey; \\ ${ }^{4}$ Department of Radiology, Faculty of Medicine, Ege University, Izmir, Turkey. \\ Email: "levent.midyat@ege.edu.tr
}

Received 7 October 2011; revised 18 November 2011; accepted 24 November 2011.

\begin{abstract}
Pulmonary hypoplasia is a rare congenital anomaly, which is frequently associated with other congenital anomalies. Clinical symptoms vary depending on the other system anomalies and severity of pulmonary hypoplasia. Although it is usually diagnosed in infancy and childhood, some cases do not show any symptoms until the adolescent ages. In adolescents and adults with unilateral hypolucent lung, although it is seen rarely, pulmonary hypoplasia should always be kept in mind. In this article, we present a case with pulmonary hypoplasia who remained asymptomatic until puberty.
\end{abstract}

Keywords: Lung; Unilateral; Hypoplasia; Adolescent

\section{INTRODUCTION}

Unilateral pulmonary hypoplasia is a rare congenital anomaly. Although its exact prevalence is not well known, it is estimated to be seen in about $1-2$ out of every 12.000 births. There is a decrease in number or size of the airways, vessels and alveoli; however, gross morphology of the lung is essentially unremarkable [1]. Hypoplastic region of the lung becomes small, fibrotic and unfunctional as a consequence of developmental delay in the alveolar tissue. Anomalies may be seen in several systems, especially in the cardiovascular, gastrointestinal, urinary and musculoskeletal systems [2-6]. Depending on the severity of hypoplasia, the patients may either be asymptomatic or may present with severe respiratory distress, and the disease usually shows its symptoms in the neonatal, infancy or childhood period [1]. In this article, a case report of a patient with this anomaly is presented who remained asymptomatic until puberty, which is a rare clinical presentation of pulmonary hypoplasia.

\section{CASE REPORT}

14-years-old male patient was admitted to our clinic with complaints of acute respiratory distress, cough, and chest pain for one day and with presumptive diagnoses of foreign body aspiration or endobronchial mass, which were considered upon finding of total volume loss in the left lung on posteroanterior chest radiograph. It was noted that medical and family history of the patient was unremarkable and he was completely asymptomatic for respiratory system and other systems until his admission to the hospital. On physical examination, reduced respiratory sounds on the left hemi-thorax, matity on percussion, systolic murmur of 2/6 intensity on the pulmonary focus was found in the patient as well as scoliosis and right medial strabismus that was noted to be congenital. Volume loss in the left lung, compensatory increase in aeration of the right lung, mediastinal shift to the left and elevation on the left diaphragm was found on posteroanterior chest radiograph of the patient whose routine hemogram, biochemical results and PPD (purified protein derivative) test were normal (Figure 1).

On bronchoscopic examination of the patient, no endobronchial lesion was found, and concentric narrowing of the left main bronchus and the left lower bronchus was observed. His respiratory function test showed restrictive and reversible obstructive pattern. The left main pulmonary artery and the left lung was hypoplastic on thoracic high-resolution computed tomography (CT) examination. Hypoplasia was found on the left main pulmonary artery also on thoracic CT and magnetic resonance (MR) angiographic examinations of the patient whose GI (gastrointestinal) barium X-ray which was taken to investigate congenital diaphragmatic hernia was normal (Figure 2). Cardiac catheterization of the patient revealed that the left main pulmonary artery was hypoplastic and he had no additional cardiac anomaly. It was decided to give the patient symptomatic treatment 


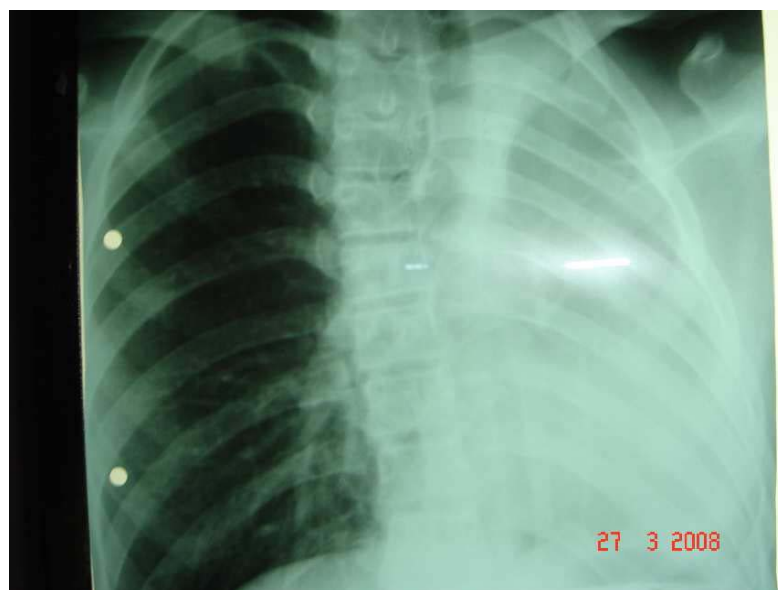

Figure 1. Hypoplasia of the left lung, compensatory increase in aeration of the right, mediastinal shift to the left, and elevation on the left diaphragm on posteroanterior chest radiograph.

and reevaluate him for operation in the case of worsening symptoms. The patient was discharged with longacting beta-2 agonist treatment.

\section{DISCUSSION}

Pulmonary hypoplasia is characterized by reduced and/or less developed lung tissue to varying degrees [710]. When pathologic specimens of the patients with pulmonary hypoplasia were examined, it was found that ratio of lung weight/body weight of the patients was less than 0.012 [11]. Development of bronchial tree occurs in 26th to 31st days of intrauterine life. Monaldi categorizes developmental disorders of the lung to four categories [12]. Group I: No bifurcation of trachea; Group II: Only rudimentary main bronchus; Group III: Uncompleted development after bifurcation of the main bronchus; Group IV: Incomplete development of small segment and subsegmental bronchi of the corresponding lobe. According to Boyden, developmental disorders are seen in three different extents [13]: 1) agenesis (complete absence of the lung tissue), 2) aplasia (no lung tissue, but there is a rudimentary bronchus), 3) hypoplasia (all lung tissues exist but under-developed). The patient presented in this article is in group IV according to Mon-

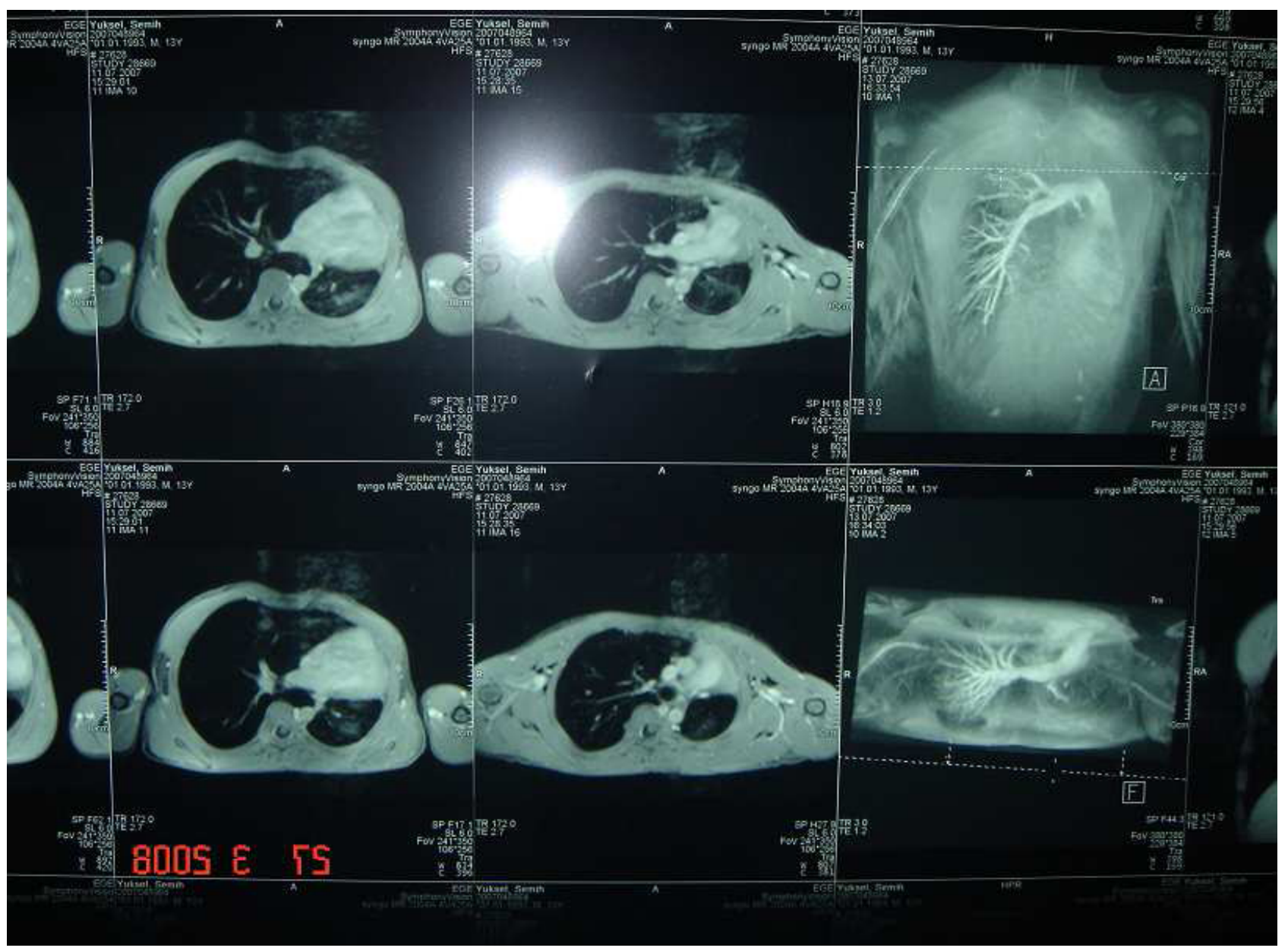

Figure 2. Hypoplasia of the left pulmonary artery and left lung on thoracic computed tomographic angiography. 
aldi classification and is of third degree according to Boyden.

There are primary (idiopathic) and secondary causes in the etiology of the pulmonary hypoplasia. It usually occurs secondary to the intrauterine diseases impairing normal lung development. Deformities of the chest wall, pleural effusion associated with hydrops fetalis, cystic adenomatoid malformation, and diaphragmatic hernia physically limits the development of the lung. Furthermore, conditions leading to oligohydramnios such as early rupture of the membranes or fetal renal insufficiency also impair development of the lungs [1]. Hypoplasia may be bilateral in thoracic dystrophies and oligohydramnios. In such cases, development of the airways and arterial truncation is inhibited and thus, surface area required for alveolo-capillary gas exchange becomes limited [1,7].

Isolated pulmonary hypoplasia is rare; it is generally accompanied by anomalies in other systems, especially in the cardiovascular, gastrointestinal, musculoskeletal and urogenital systems. Severity of the clinical symptoms and timing of their occurrence is related to the degree of hypoplasia [14]. It usually presents with respiratory distress or pulmonary hypertension in the newborn period. Respiratory distress in the first five minutes following birth is typical for these patients, and they usually require mechanical ventilation. Apgar scores are usually found to be lower, although babies with completely normal Apgar scores may also be seen [11, 15-19]. However, as in our patient, patients who remain asymptomatic until puberty have also been reported [7,9, 10]. Total atelectasia, pleural effusion, pneumonia, diaphragmatic elevation, diaphragmatic hernia, pulmonary aplasia, and pneumonectomy should be considered in differential diagnosis of these patients. Postero-anterior chest radiograph, thoracic CT, CT angiography, MR angiography and bronchoscopy may be used for diagnosis [14]. Some pathologists suggested that radial alveolar counting (RAC) might be used for confirming the diagnosis of hypoplasia [20]. In this method, number of the alveoli taken from a region between the respiratory bronchiole and the closest connective tissue is compared to a normal control sample in the same laboratory. This rate was found to be reduced in two published studies [11,15,21-24], although another study did not support this assumption [18].

Life-span of the patients depends on severity of anomalies of other systems and degree of the pulmonary hypoplasia [1]. Mortality has been reported to be high (71\% - 95\%) especially in those cases manifesting in the newborn period $[11,25]$. Membrane rupture earlier than 25th week of the gestation, presence of severe oligohydramnios (amniotic fluid index $<4$ ) for more than 2 weeks, and preterm labor have been reported to be conditions increasing mortality [25]. Some prenatal interventions may be attempted to increase fetal lung capacity or to provide lung development, depending on the underlying etiologic reason. Tocolitics for early membrane rupture, antibiotics, steroids, use of fibrin glue to correct the lesion transcervically, and consecutive use of amnio-infusions are methods used currently in several centers and of which benefits have been reported in some references [25]. Additionally, other methods in the postnatal period include mechanical ventilation, providing ECMO (extracorporeal membrane oxygenation) and surfactant support, and early initiation of dialysis to support renal function. No method with proven efficacy has been found although some surgical techniques are being tried [25].

Unilateral hypoplasia is a congenital anomaly causing a wide spectrum of clinical manifestations from mild, non-specific findings to severe respiratory symptoms. Our case was presented with nonspecific findings, who remained asymptomatic until puberty, which is a rare clinical presentation of pulmonary hypoplasia. In patients with unilateral hypolucent lung, although it is seen rarely, pulmonary hypoplasia should always be kept in mind.

\section{REFERENCES}

[1] Kant, S. (2007) Unilateral pulmonary hypoplasia-A case report. Lung India, 24, 69-71. doi:10.4103/0970-2113.44215

[2] Hislop, A., Hey, E. and Reid, L. (1979) The lungs in congenital bilateral renal agenesis and dysplasia. Archives of Disease in Childhood, 54, 32-38. doi:10.1136/adc.54.1.32

[3] Areechon, W. and Reid, L. (1963) Hypoplasia of lung with congenital diaphragmatic hernia. British Medical Journal, 1, 230-233. doi:10.1136/bmj.1.5325.230

[4] Johnson, R.J. and Haworth, S.G. (1982) Pulmonary vascular and alveolar development in tetralogy of fallot: A recommendation for early correction. Thorax, 37, 893901. doi:10.1136/thx.37.12.893

[5] Cooney, T.P. and Thurlbeck, W.M. (1985) Lung growth and development in anencephly and hydranencephaly. The American Review of Respiratory Disease, 132, 596601.

[6] Cooney, T.P. and Thurlbeck, W.M. (1982) Pulmonary hypoplasia in Down syndrome. New England Journal of Medicine, 307, 1170-1173. doi:10.1056/NEJM198211043071902

[7] Deniz, Ö., Tozkoparan, E., Çiftçi, F., Özkan, M., et al. (2004) Sol pulmoner aplazi (agenezi) (olgu sunumu). Gülhane Tıp Dergisi, 46, 56-58.

[8] Fraser, R.S., et al. (Eds.) (1994) Pulmonary abnormalities of developmental origin. Synopsis of diseases of the chest, Second Edition, W. B. Saunders Company, Phildelphia, 256-286. 
[9] Naclerio, E.A. (1959) Congenital diseases, agenesis of lung. Bronchopulmonary Diseases, 35, 309-313.

[10] Roque, A.S., Burton, E.M., Boedy, R.F., Falls, G., et al. (1997) Unilateral pulmonary agenesis without mediastinal displacement. Southern Medical Journal, 90, 335337.

[11] Odd, D.E., Batin, M.R., Halam, L. and Knight, D.B. (2003) Primary pulmonary hypoplasia: A case report and review of the literature. Journal of Paediatrics and Child Health, 39, 467-469. doi:10.1046/j.1440-1754.2003.00191.x

[12] Monaldi, V. (1960) Malformative bronchopulmonary diseases caused by anatomical defects. Minerva Medica, 51, 3474-3478.

[13] Boyden, E.A. (1955) Developmental anomalies of the lungs. American Journal of Surgery, 89, 79-89. doi:10.1016/0002-9610(55)90510-9

[14] Haddad, G.G. and Fontan, J.J.P. (2000) Development of the respiratory system. Nelson Textbook of Pediatrics, 16th Edition, 1235-1237.

[15] Swischuk, L.E., Richardson, C.J., Nichols, M.M. and Ingman, M.J. (1979) Primary pulmonary hypoplasia in the neonate. Journal of Pediatric, 95, 573-577. doi:10.1016/S0022-3476(79)80773-8

[16] Sunam, G. and Ceran, S. (2009) Pulmonary artery agenesis and kung hypoplasia. European Journal of General Medicine, 6, 265-267.

[17] Mendelsohn, G. and Hutchins, G.M. (1971) Primary pulmonary hypoplasia. Report of a case with polyhydramnios. American Journal of Diseases of Children, 131,
1220-1223.

[18] Frey, B., Fleishauer, A. and Gersbach, M. (1994) Familial isolated pulmonary hypoplasia: A case report, suggesting autosomal recessive inheritance. European Journal of Pediatrics, 153, 460-463. doi:10.1007/BF01983413

[19] Hamel, B.C.J. (1995) Familial primary pulmonary hypoplasia. European Journal of Pediatrics, 154, 336. doi:10.1007/BF01957378

[20] Askenazi, S.S. and Perlman, M. (1979) Pulmonary hypoplasia: Lung weight and radial alveolar count as criteria of diagnosis. Archives of Disease in Childhood, 54, 614-618. doi:10.1136/adc.54.8.614

[21] Langer, R. and Kaufmann, H.J. (1986) Primary (isolated) bilateral pulmonary hypoplasia: A comparative study of radiologic findings and autopsy results. Pediatric Radiology, 16, 175-179. doi:10.1007/BF02456280

[22] Laudy, J.A., Tibboel, D., Robben, S.G., de Krijger, R.R., et al. (2002) Prenatal prediction of pulmonary hypoplasia. Clinical, biometric, and doppler velocity correlates. $\mathrm{Pe}$ diatrics, 109, 250-258. doi:10.1542/peds.109.2.250

[23] Chang, N., Hertzler, J.H., Gregg, R.H., Lofti, M.W., et al. (1968) Congenital stenosis of the right mainstem bronchus. A case report. Pediatrics, 41, 739-742.

[24] Goldstein, J.D. and Reid, L.M. (1980) Pulmonary hypoplasia resulting from phrenic nerve agenesis and diaphragmatic amyoplasia. Journal of Pediatric, 97, 282287. doi:10.1016/S0022-3476(80)80496-3

[25] Chin, T. (2009) Pulmonary hypoplasia. Cited March 2009. http://www.emedicine.com/ped/TOPIC2627.HTM 